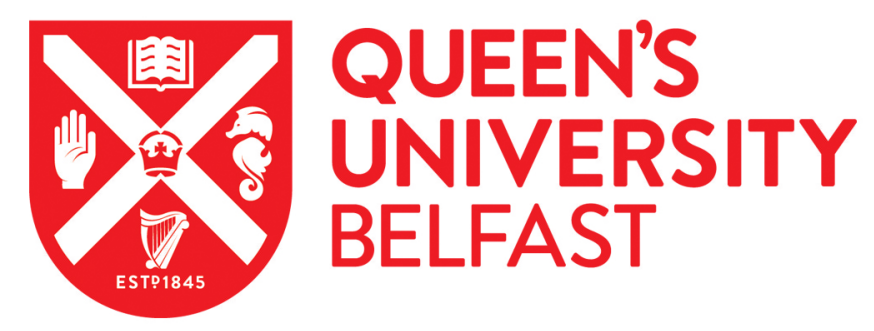

\title{
Islanding Detection for Distributed Generation
}

Ding, X., Crossley, P., \& Morrow, D. J. (2007). Islanding Detection for Distributed Generation. Journal of Electrical Engineering and Technology, 2(2), 19-28.

Published in:

Journal of Electrical Engineering and Technology

Queen's University Belfast - Research Portal:

Link to publication record in Queen's University Belfast Research Portal

\section{General rights}

Copyright for the publications made accessible via the Queen's University Belfast Research Portal is retained by the author(s) and / or other copyright owners and it is a condition of accessing these publications that users recognise and abide by the legal requirements associated with these rights.

Take down policy

The Research Portal is Queen's institutional repository that provides access to Queen's research output. Every effort has been made to ensure that content in the Research Portal does not infringe any person's rights, or applicable UK laws. If you discover content in the Research Portal that you believe breaches copyright or violates any law, please contact openaccess@qub.ac.uk. 


\title{
Islanding Detection for Distributed Generation
}

\author{
X. Ding*, P. A. Crossley* and D. J. Morrow*
}

\begin{abstract}
The paper discussed various techniques for islanding detection and described in detail the working principles of ROCOF and vector shift relays. A simulator was used to investigate why the stability of both types of relays maybe affected by network and load switching, short-circuit faults and in the case of a ROCOF relay the loss of bulk generation or the tripping of a transmission feeder. Finally, to enhance the reliability of Loss of Mains protection, a new islanding detection technique based on a GPS synchronized phasor measurement system was proposed.
\end{abstract}

Keywords: Distributed generation, islanding detection, ROCOF, Vector shift, LOM.

\section{Introduction}

The operation of generators in parallel with a utility based, electrical distribution network poses several problems for the network, of which the most challenging is islanding. Islanding, loss of mains [1] or loss of grid is a generic term used to describe a scenario where a section of the distribution network is supplied by a generator isolated from the main utility supply [2]. This creates the problem in terms of maintaining an acceptable power quality to the customer in the formed island, poses a hazard to utility personnel involved in the restoration of the network and risks damage to plant if the island is reconnected without synchronization. Thus islanding detection is required by G59 [3] for any generator that wants to be connected to an electrical distribution network in the United Kingdom. Such a generator is normally referred to as a Distributed Generator (DG) and islanding or loss of mains (LOM) protection must be installed on its intertie to the utility network; i.e. the DG must not be allowed to supply a part of the distribution network once it has become electrically isolated from the main grid supply.

Techniques proposed for islanding detection can be generally divided into two categories: Active methods and passive methods. Passive methods are based on monitoring one or more system parameters and they make their trip decision without directly interacting with system operation [4]. They work based on the assumption that in almost all circumstances a loss of mains will result in a measurable variation in voltage, frequency and/or power [5]. Active methods directly and actively interact with the power system to detect the part of the network that has been islanded.

\footnotetext{
* Queen's University of Belfast, Belfast, UK (x.ding@ee.qub.ac.uk, p.crossley@qub.ac.uk,dj.morrow@ee.qub.ac.uk) Received 19 July, 2006 ; Accepted 28 December, 2006
}

The main passive techniques proposed for islanding protection include Rate Of Change Of Frequency (ROCOF) [6], Vector Shift, Under/Over frequency, Under/Over Voltage and Reverse VAr. Beside these schemes, many other passive techniques have been proposed for islanding detection such as change of output power [7][8][9], rate of change of voltage and power factor [10], an elliptical trajectory technique [11], ratio of the frequency change to the output power change $\partial \mathrm{f} / \partial \mathrm{P}[12]$, and voltage unbalance and total harmonic distortion (THD) [13]. The main active techniques for islanding detection are reactive power error export detection (REED) [14], fault level monitoring [6], and system impedance monitoring [4].

Active methods are generally considered more effective and robust than passive methods because they detect islanding by continuously interacting with the output of the DG. However schemes that interact by injecting small disturbances into the network might have an adverse impact on power quality and the dynamics of the overall system [15]. Furthermore their effectiveness maybe a problem if multiple DGs are contained in the islanded network; this introduces the possibility of interference between the signals or disturbances injected at each DG [16][17].

Therefore for such technical reasons, and perhaps more importantly higher cost, active methods are not favored by industry and are rarely implemented.

Passive methods for loss of mains protection dominate due to their simplicity and low cost; and of these ROCOF and vector shift are the most widely used. Although popular, problems in their application are experienced if the load and generation on the part of the network that becomes islanded are closely matched; this limitation is recognised in Engineering Recommendation (ETR) 113 [18] section 3.4.5. Furthermore, passive method can, on some networks, fail to discriminate between an actual LOM and other transient events. Nuisance tripping can 
occur if the system frequency varies suddenly due to load switching, loss of bulk generation or network faults.

If conventional LOM techniques are not sufficient to prevent islanding, then a transfer-trip scheme with a reliable means of communication may be necessary [19]. A transfer trip scheme, also referred to 'Inter-tripping' [20], is conceptually different from the above-mentioned passive and active techniques in that it does not operate based on measuring any electrical system parameters. It works on the basis of monitoring the open or closed status of all the circuit breakers and re-closers in the utility network that could result in a DG supporting an island without a connection to the utility network. A transfer trip scheme does not suffer the problem of a non-detection zone like other LOM techniques and for distribution feeders with fixed topology it can be very effective. However if the feeder topology changes, the transfer scheme can become complicated and expensive to apply.

The paper describes the working principle of the ROCOF and Vector Shift Relay, looks at the factors that affect their detection capability, such as the inertia constant of the distributed generator and the load power factors and compares the performance of these two methods. It also studies their performance during system transients. The latter section of this paper describes a new LOM detection technique based on a GPS synchronized phasor measurement system that compares the angular difference between the utility network voltage phasors and the distributed generator voltage phasors. The performance of the proposed technique is shown to be more reliable than ROCOF.

\section{Working Principles of ROCOF and Vector shift}

deficit exists between the load and the generation in the formed island. Immediately after islanding, the power imbalance between the load and generation causes a sudden change of frequency, which has been used to detect loss of mains. The immediate rate of change of frequency after islanding is a function of the power imbalance in the island and the inertia of the distributed generator (see equation 1).

$$
\frac{d f}{d t}=-\left(\frac{P_{L}-p_{G}}{2 H \times S_{G N}} \times f_{r}\right)
$$

where $\mathrm{P}_{\mathrm{G}}=$ output of distributed generator,

$\mathrm{S}_{\mathrm{GN}}=$ rated capacity of generating plant

$\mathrm{H}=$ inertia constant of generating plant

$\mathrm{f}_{\mathrm{r}}=$ rated frequency.

If the resulting rate of change of frequency exceeds the threshold, a trip signal will be triggered. ROCOF settings for a $50 \mathrm{~Hz}$ power system could range from $0.1 \mathrm{~Hz} / \mathrm{s}$ to $1.0 \mathrm{~Hz} / \mathrm{s}$ [4]. The value depends on the strength of the system, the stronger the system, the lower the setting. In Great Britain, ROCOF relays are usually set at $0.125 \mathrm{~Hz} / \mathrm{s}$, and in Northern Ireland at $0.45 \mathrm{~Hz} / \mathrm{s}$ to $0.5 \mathrm{~Hz} / \mathrm{s}$.

A problem with ROCOF relays is that products from different manufacturers often respond differently to the same system event, even when they are conFig.d with the same settings. This is due to subtle differences between the algorithms used to interpret the Rate Of Change Of Frequency. Some ROCOF relays use zero-crossing algorithms, whilst others use DFT (Discrete Fourier Transform) algorithms to measure the frequency. Hence, the operating response may vary during the same system disturbance. Secondly, the way to define rate of change of frequency differs; normally the duration of the measuring window is 3 to 6 cycles, but longer windows are occasionally used. Generally, the shorter the window, the higher the sensitivity but the lower the reliability.

Vector shift is also referred to as phase displacement, phase jump or vector surge. It detects the islanding condition based on monitoring the phase change of the local voltage. Fig. 1 shows the normal situation in which the DG runs in parallel with the utility network and supplies part of the load. The distribution network, including the DG, are represented by an equivalent circuit. The synchronous electromotive force will lead the terminal voltage of the DG by a rotor angle displacement $\mathrm{a}^{\circ}$, which is defined by the voltage difference between $\mathrm{Ef}$ and $\mathrm{Vt}$ as illustrated in the phasor diagram of Fig. 1.
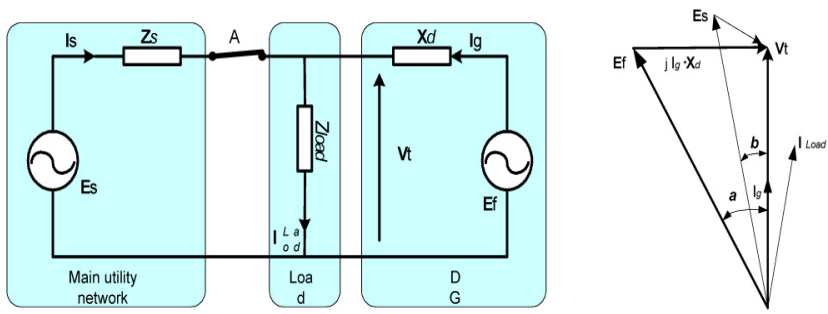

Fig. 1. Equivalent circuit of a DG operating in parallel with the network and the corresponding phasor diagram.

If the main utility supply is removed by opening switch A, see Fig. 2, the sudden increase of load on the DG will result in a near instantaneous rotor angle change. This can be represented by a voltage phasor jump to a new position. The synchronous electromotive force will lead the terminal voltage of the DG by a new rotor angle displacement a' as illustrated in Fig. 2 and Fig. 3, in which the new terminal voltage after islanding is depicted by the solid line and the previous terminal voltage is depicted by the dotted line. 

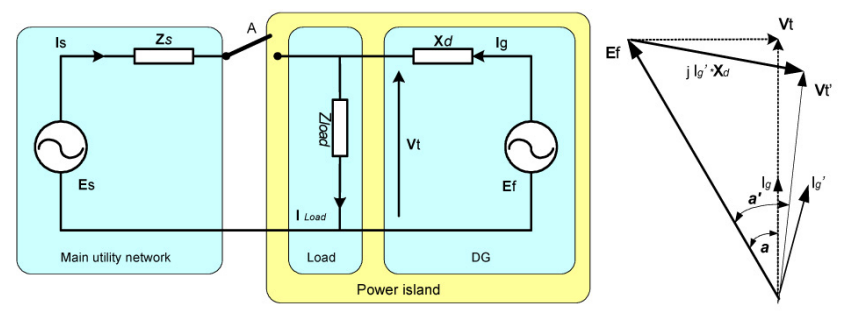

Fig. 2. Equivalent circuit of a DG in island mode and the corresponding phasor diagram

The relay will initiate instantaneous tripping of the DG once the change of the monitored voltage phase angle exceeds the defined setting. Common settings for voltage vector shift relays are in range between 6 and 12 degrees. A relatively high setting is recommended on weak networks to prevent mal-operation when switching on or off heavy consumer loads. In the UK typical vector shift settings suggested by ETR 113 are $6^{\circ}$ in mainland UK and $10^{\circ}-12^{\circ}$ in Northern Ireland.

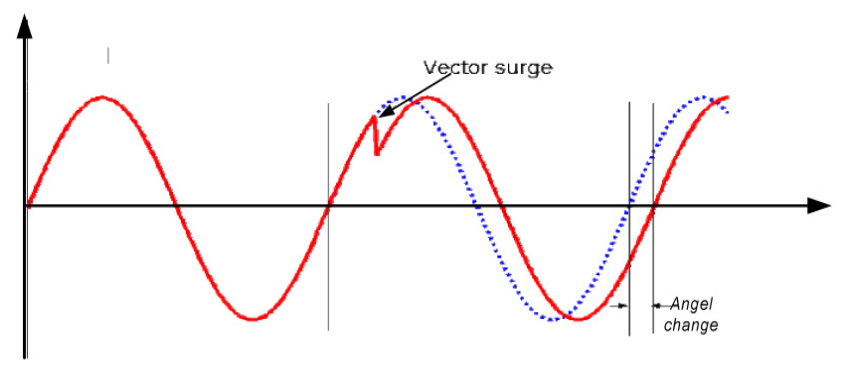

Fig. 3 Voltage waveform of DG at the instant of loss of mains.

A vector shift relay captures the voltage angle change by measuring the change in the time duration between zero crossings on the voltage waveforms. A new measurement is started at each voltage zero passage. The measured cycle duration is internally compared with previous cycle duration reference. At the moment the DG becomes disconnected, the sudden change in load causes a sudden change in the cycle length as pictured in Fig. 3 using a solid line. The cycle length becomes shorter or longer depending whether the newly formed island has a surplus or shortage of generation. The deviation of duration time from the previous cycle reference is used to indicate the change of angle in the vector shift relay.

Although the principle of vector shift is simple, the actual performance of a vector shift relay depends on how the algorithm has been implemented by the relay manufacturer. One of the key elements is how to define the reference cycle duration and how to compare it with the current cycle duration. Effort has been made to investigate the techniques used in vector shift relays supplied by different manufacturers. The results reveal considerable variations. For example, some manufacturers use a quartz oscillator to define the duration of the previous cycle and then use this as the reference, whilst others use a reference based on the average duration of a number of previous cycles; values between 5 and 32 cycles are used. In addition, some relays operate in a three-phase mode, whilst others use single-phase quantities. Single-phase is more sensitive in detecting a vector shift due to a loss of grid, however it is also more sensitive to the effect of spurious disturbances. Studies in [21] illustrate the variation in the performance of ROCOF and Vector shift relays supplied by different manufacturers.

The effectiveness of vector shift in detecting loss of grid is related to the magnitude of the instantaneous change in the DG power output. It is therefore vulnerable to the problem of non-detection of grid disconnection when the load and generation mismatch is inadequate. The minimum generation mismatch required to activate the relay is normally about $15 \%-20 \%$ of the rated power. With a setting of 10 degrees, the power imbalance required to detect loss of grid may need to be greater than $30 \%$ [20].

A vector shift relay is not sensitive to the change in voltage phase brought about by the change of frequency alone. This can be explained by considering a sinusoidal voltage waveform: $-V=V m \operatorname{Cos} \theta(t)=V m \operatorname{Cos}(\omega t)$. If the frequency is changing at constant rate $\delta_{f} \mathrm{~Hz} / \mathrm{s}$, starting at frequency $f_{0}$ then the variation in the phase angle is given by:

$$
\theta(t)=2 \pi \int f \cdot d t=2 \pi \int\left(f_{0}+\delta_{f} \cdot t\right) \cdot d t=2 \pi\left(f_{0} \cdot t+\delta_{f} \cdot t^{2} / 2\right)
$$

Hence the angle change $\Delta \theta(t)$ is given by $\Delta \theta(t)=\pi \delta_{f} t^{2}$

To quantify the expected value of vector shift consider a rate of change of frequency of $2.0 \mathrm{~Hz} / \mathrm{s}$ which results in a vector shift of only 0.288 degree at the first cycle after islanding; this is too small to be detected.

It is very important to be aware that vector shift is susceptible to network faults outside the island zone. Also power system switching events, not resulting in islanding, can sometime falsely operate the relay with sensitive settings. False tripping events in mainland UK network resulting from mal-operation of vector shift relays were reported in [21]. Obviously, increasing the setting of the relay can enhance reliability and reduce the possibility of nuisance tripping, but it makes the relay less sensitive in detecting islands. 


\section{Factors affecting rocof relays}

The operating performance of a ROCOF relay is closely related to the power imbalance in the formed island at the instant of islanding. The higher the setting, the larger the power imbalance required to operate the relay. For the same setting, a high power imbalance results in fast detection. Many factors affect the actual power imbalance, including load type, power factor and the inertia of the DG. The effect of these factors on a typical ROCOF relay is illustrated below.

Fig. 4 shows the network model used in the study; the $\mathrm{DG}$ is a $690 \mathrm{~V}$ synchronous generator connected to the $11 \mathrm{kV}$ busbar-4 via a transformer. When the feeder is islanded by opening circuit breaker (CB), the generator $\mathrm{G}$, equipped with AVR and speed control, automatically picks up the load and restores the voltage and frequency.

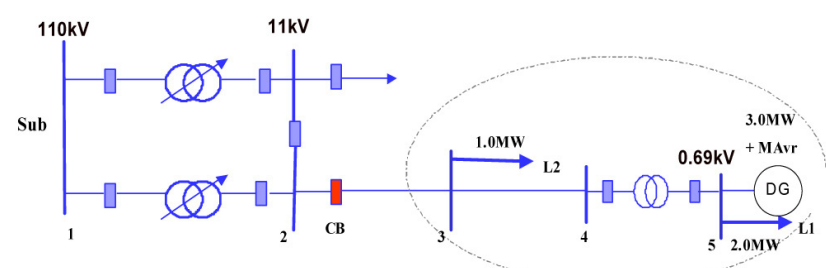

Fig. 4. Distribution network with DG connected .

The ROCOF relay model used in the study of ROCOF performance is demonstrated in Fig. 5. The three phase voltage signals at the Distributed generator terminal are sent to the PLL (Phase Locked Loop). This derives a fundamental frequency signal, which is processed with a derivation calculation. The resulting signal is transferred to a First order transfer function with a time constant Ta that represents the time constant of the filters and the adopted measurement window.

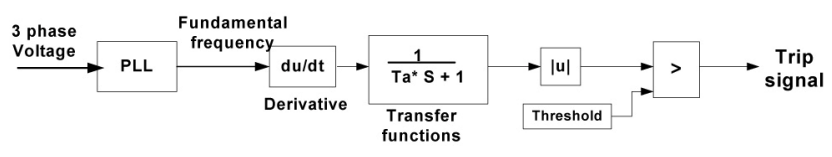

Fig. 5. Block diagram of model of ROCOF relay

The effect on a ROCOF relay of constant power, constant current and constant impedance loads is investigated in this simulation study. Fig. 6 shows the minimum power imbalance required to activate the relay when set at $0.5 \mathrm{~Hz} / \mathrm{s}$. A higher power imbalance is required to activate the relay when operating with a constant impedance load; this is because the power of the load is proportional to (voltage)2. With a constant current load, the power is proportional to voltage. At the instant of islanding, a voltage reduction normally occurs, and the load will be reduced. The reduction is greatest for a constant impedance load and negligible for a constant power load. For the case of real and reactive power deficit, the power imbalance decreases, because the load reduces with voltage. However, for a real power surplus, the voltage and the load will still reduce, but now the power imbalance increases. For the first scenario, ROCOF becomes less sensitive, whilst for the second, more sensitive. Having illustrated the effect on a ROCOF relay of the type of load, the simulation studies used in the remainder of this paper will now assume a constant impedance load.

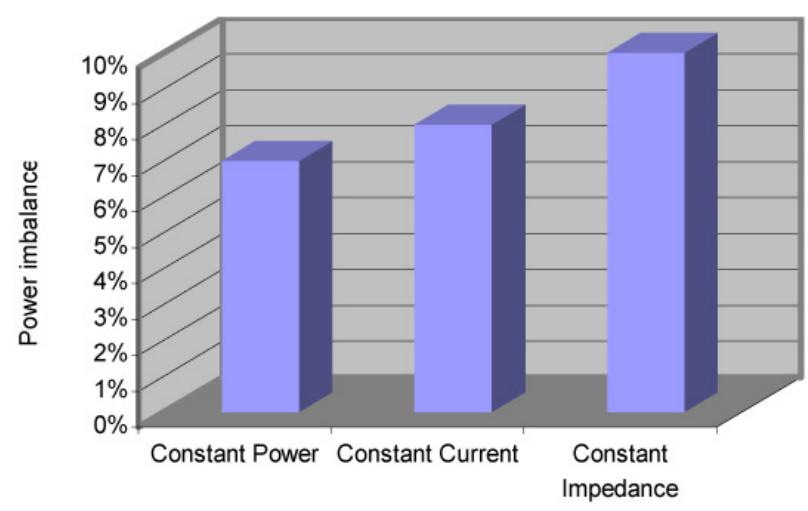

Fig. 6. Minimum power imbalance required to active the relay $(0.5 \mathrm{~Hz} / \mathrm{s})$ when different load types are used.

The power factor of a load affects the power imbalance because it changes the voltage profile. The lower the power factor, the greater the voltage reduction at the time of islanding. Thus for the voltage dependent load, there is a reduction in the generation imbalance. This makes it more difficult for a ROCOF relay to detect islanding. With the power imbalance kept at $10 \%$, the performance of the ROCOF relay at different load power factors $(1.0-0.85)$ is investigated. The results are summarised and presented in Table 1; note: a relay set at $0.5 \mathrm{~Hz} / \mathrm{s}$ fails to operate when the load power factor is 0.9 or less.

Table 1. Effect of load power factor on ROCOF.

\begin{tabular}{|c|c|c|}
\hline $\begin{array}{c}\text { Load } \\
\text { PF } \\
\text { (p.u.) }\end{array}$ & $\begin{array}{c}\text { Rocof } \\
0.2 \mathrm{~Hz} / \mathrm{s}\end{array}$ & $\begin{array}{c}\text { Rocof } \\
0.5 \mathrm{~Hz} / \mathrm{s}\end{array}$ \\
\hline 1 & trip & Trip \\
\hline 0.95 & trip & Trip \\
\hline 0.9 & trip & ${ }^{*}$ \\
\hline 0.85 & trip & ${ }^{*}$ \\
\hline
\end{tabular}

In addition, the inertia constant of the DG also affects the performance of a ROCOF relay. The simulation result in Fig. 7 illustrates the frequency variation with respect to inertia constants of $1.0 \mathrm{~s}$ and $1.5 \mathrm{~s}$, under the same islanding condition. The higher the inertia constant, the slower the 
rate of change of frequency, and the less sensitive the relay; this is explained by Equation 1. Therefore even with the same islanding condition, the operating performance of a ROCOF relay depends on the DG characteristics.

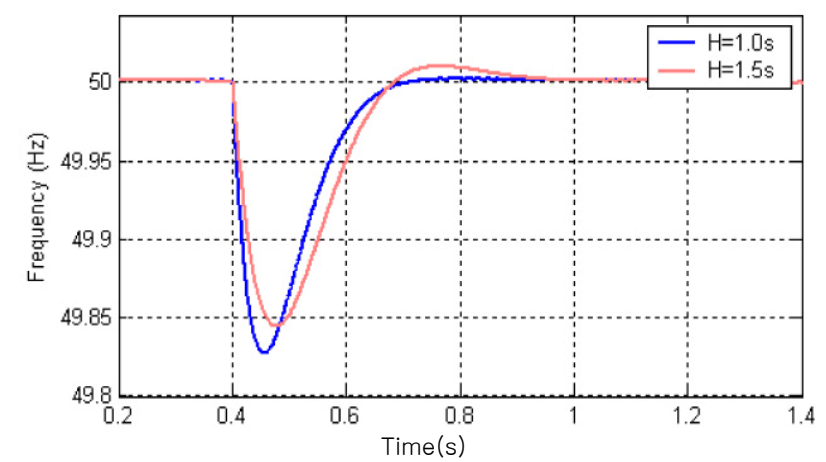

Fig. 7. Frequency variation in islanding with respect to different inertia constant of DG

\section{Comparison of ROCOF and Vector Shift}

To investigate the performance of ROCOF and Vector shift relays during islanding conditions and system disturbances, the following case studies were carried out. The network model used in the simulation studies is shown in Fig. 8.

\subsection{Relay Model}

The model of the vector shift relay and the ROCOF relay applied in the simulation studies were developed in Matlab using a zero-crossing technique similar to that used in an existing processor based LOM relay. The instantaneous values of the DG terminal voltage generated by the simulator are sent to the ROCOF and the vector shift relay models. Once the processed value exceeds the setting, the vector shift relay immediately initiates a trip. Whilst the ROCOF relay uses a 4-cycle window and requires two consecutive processed values to exceed the threshold before a trip signal is initiated. Note: once the relay model decides to trip, the simulation recognises this as the operating time.

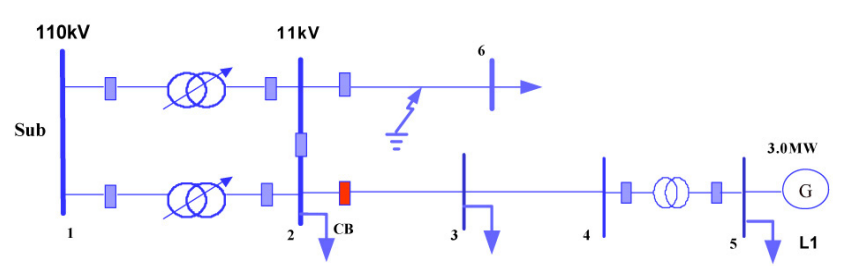

Fig. 8. Network diagram used in the simulation.

Case-a. An investigation into the difficulty of detecting islanding using ROCOF or vector shift relays when the load and generation are exactly matched. Islanding is simulated by opening the circuit breaker CB.

A very small frequency deviation occurred after the islanding. The ROCOF relay with a setting of $0.5 \mathrm{~Hz} / \mathrm{s}$ and a vector shift relay with a setting of $6^{\circ}$ failed to detect the islanding. The test was then repeated with ROCOF setting at $0.125 \mathrm{~Hz} / \mathrm{s}$ and the vector shift setting at $2^{\circ}$. Again both relays failed to detect islanding.

Case-b. A study into the effect of network switching actions on ROCOF and vector shift relays.

Consider switching-out one of the parallel $110 \mathrm{kV} / 11 \mathrm{kV}$ transformers: a ROCOF relay set at $0.5 \mathrm{~Hz} / \mathrm{s}$ incorrectly operates, whilst a vector shift relay set at $6^{\circ}$ remains stable. Tests are repeated whilst reducing the setting of the vector shift relay, the relay tripped at a setting of $3^{\circ}$.

The incorrect operation of ROCOF is due to the phase shift resulting from the switching event. This is because the phase shift will result in an incorrect calculation of $\mathrm{df} / \mathrm{dt}$ particularly when the duration of the measuring window is small. It was found that the closer the electrical distance of the load from the generator, the greater the effect "switching on/off load" has on a ROCOF relay, which makes it more prone to nuisance tripping. To enhance the reliability of ROCOF, it is required that the relay monitors the rate of change of frequency over a few successive cycles before issuing the trip command. If six consecutive processed values are required to exceed the threshold before a trip signal is initiated, the ROCOF with $0.5 \mathrm{~Hz} / \mathrm{s}$ failed to trip. The setting was reduced to $0.125 \mathrm{~Hz} / \mathrm{s}$, but the relay still failed to trip.

Case-c. Investigation into the effect of network faults on ROCOF and vector shift relays.

A three-phase fault was applied on the adjacent feeder at bus $4,120 \mathrm{~ms}$ later the fault was cleared by circuit breaker. Both the ROCOF relay $(0.5 \mathrm{~Hz} / \mathrm{s})$ and the vector shift relay $\left(6^{\circ}\right)$ incorrectly operated as illustrated in Fig. 12.

A ROCOF relay with a setting of $1.0 \mathrm{~Hz} / \mathrm{s}$ and a vector shift relay with a setting of $10^{\circ}$ were also tested. Both relays failed to discriminate between a real islanding event and the adjacent feeder fault. To prevent mal-operation of the vector shift relay on the adjacent feeder fault it was necessary to raise the setting to $12^{\circ}$. However, with this setting the relay will be unable to detect some realistic islanding events. Note:- the effect of a fault on a ROCOF or vector shift relay depends on the electrical distance between the fault and the DG.

An alternative solution that increases the stability of the vector shift relay during a fault is to restrain the relay using an under-voltage level detector. 


\subsection{Impact of loss of bulk generation infeed}

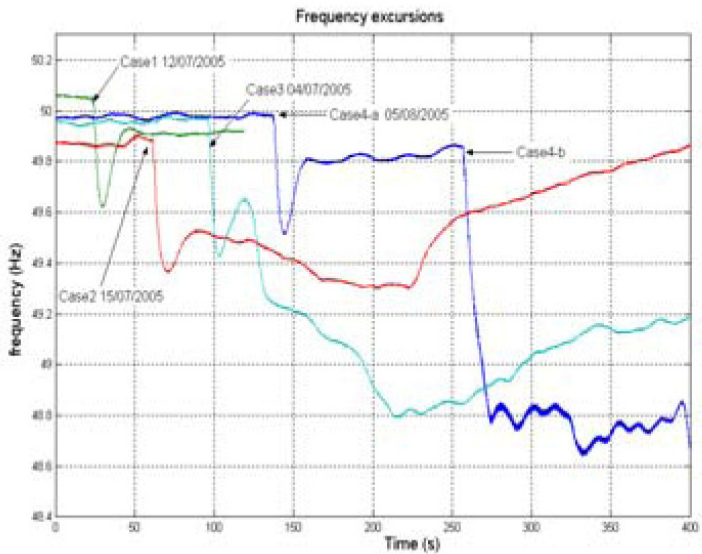

Fig. 9. Frequency excursions seen on NI network.

A major concern about the use of ROCOF and vector shift relays is that a severe under-frequency transient can occur when a bulk generator infeed is lost and this might lead to the system wide tripping of distributed generators. In Great Britain, it is considered that such events could result in a rate of change of frequency of up to $0.2 \mathrm{~Hz} / \mathrm{s}$ and this might affect the stability of the ROCOF relays used by the DG to detect islanding. In weaker systems, such as the all-Ireland electricity network, sudden frequency excursions are regular events and the loss of a bulk generator or an important transmission feeder can be a major problem. Four real cases of frequency disturbances seen on the N.Ireland network are presented in Fig. 9, these occurred on $8^{\text {th }}$ August, $12^{\text {th }}$ July, $15^{\text {th }}$ July and $4^{\text {th }}$ July 2005. These case studies were chosen to investigate how the rate of change of frequency calculated by a ROCOF relay with a 4 cycle operating window responded to the disturbance. The rate of change of frequency seen by ROCOF relay corresponding to each disturbance case is given in Fig. 10 to Fig. 14.

It can be observed, with reference to the results in Fig. 10 to Fig. 14, that the magnitude of the rate of change of the frequency for these disturbances can be significant at the beginning of the frequency excursion. They all exceed $0.3 \mathrm{~Hz} / \mathrm{s}$ at the start of the disturbance and the maximum one goes to $0.43 \mathrm{~Hz} / \mathrm{s}$ in case 1 . If the relay setting is smaller than this, the generator protected by the ROCOF relay will be tripped.

The test results obtained from ROCOF model for the above case studies are presented in table 3. Here, the ROCOF relay uses a 4-cycle window and requires four consecutive processed values to exceed the threshold before a trip signal is initiated. It can be observed that the ROCOF relay is very sensitive to these frequency disturbance events. ROCOF can trip with setting below $0.31 \mathrm{~Hz} / \mathrm{s}$.

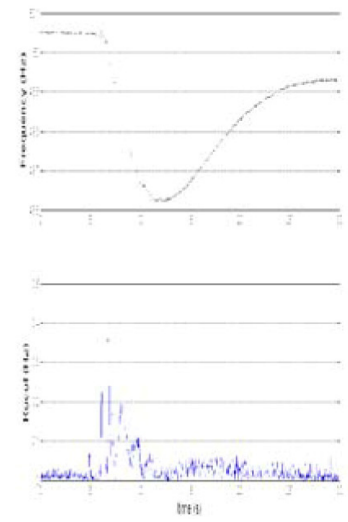

Fig. 10. Case1 12/07/2005
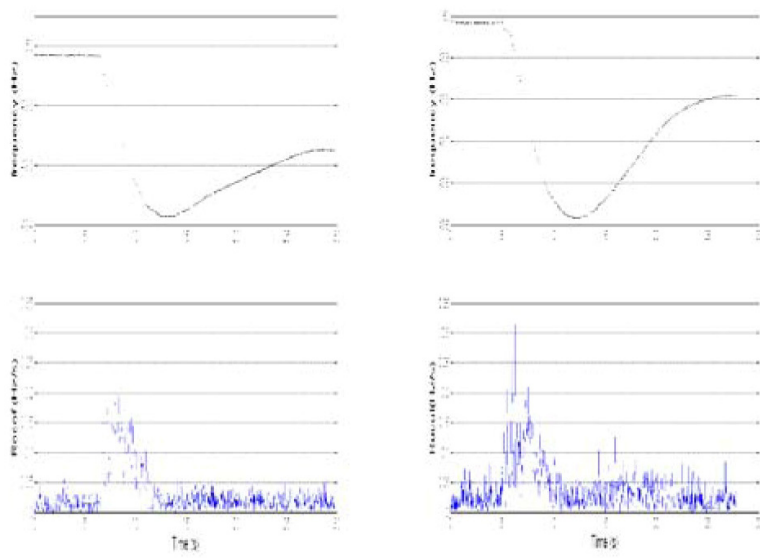

Fig. 12. Case 04/07/2005

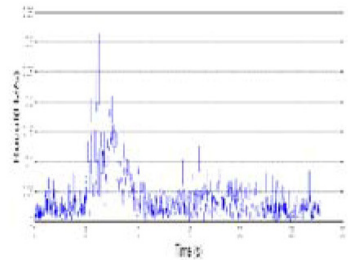

Fig. 13. Case 4 a 05/08/2005
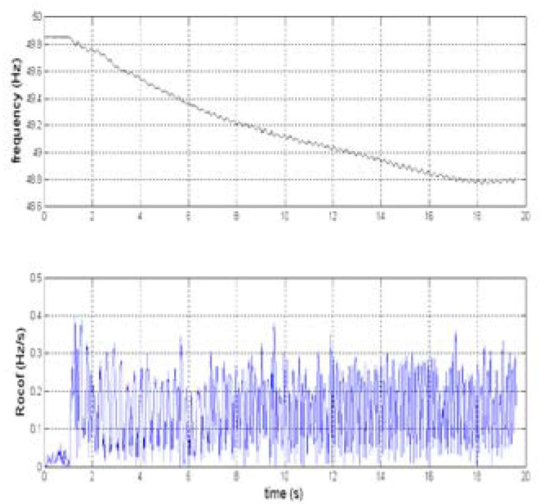

Fig. 14. Case4b 05/08/2005

During a more severe under-frequency disturbance, the rate of change of the frequency on the N.Ireland network can be greater than $0.45 \mathrm{~Hz} / \mathrm{s}$ and large numbers of DG will be tripped. Such behavior only aggravates the situation and further risks the integrity of the network. That is because the loads previously supplied by DG now have to be supplied from bulk generators connected to an already heavily stressed transmission network. In the foreseeable future, the installed capacity of DG is likely to become significant and maintaining network security, particularly when one considers the limitations of ROCOF relay, will 
demand more conventional spinning reserve, which is obviously costly and undesirable. Utilizing a longer time delay might help to strengthen the reliability of the ROCOF relay. This, however, also significantly reduces the sensitivity of the relay.

\section{Table 2.}

\begin{tabular}{|c|c|c|}
\hline Relay type & $\begin{array}{c}\text { ROCOF } \\
(\mathrm{Hz} / \mathrm{s})\end{array}$ & $\begin{array}{c}\text { Vector Shift } \\
(2 \mathrm{deg})\end{array}$ \\
\hline Case 1 & $0.29 \mathrm{~Hz} / \mathrm{s}$ & $/$ \\
\hline Case 2 & $0.3 \mathrm{~Hz} / \mathrm{s}$ & $/$ \\
\hline Case 3 & $0.25 \mathrm{~Hz} / \mathrm{s}$ & $/$ \\
\hline Case $4 \mathrm{a}$ & $0.25 \mathrm{~Hz} / \mathrm{s}$ & $/$ \\
\hline Case $4 \mathrm{~b}$ & $0.31 \mathrm{~Hz} / \mathrm{s}$ & $/$ \\
\hline
\end{tabular}

For comparison, these disturbance cases are also tested with our vector shift relay model. The results are presented in table 3, where '/' represents stability or a non-trip. This implies that the vector shift relay is not sensitive to system frequency disturbances.

Based on the above case studies, it can be seen that selecting the correct "sensitive, but stable" setting for a ROCOF or vector shift relay is very difficult. There is no single setting suitable for all scenarios and each case requires individual study. Furthermore, the impact of widespread false tripping of is likely to become an even more important problem in the near future. Consequently, a more appropriate method for islanding detection is urgently required.

\section{Detection of LOM using angular difference}

To solve the problem of nuisance tripping, a new passive islanding detection technique based on a GPS synchronized measurement system is proposed in the last part of this paper [23]. The technique compares the angular difference between the utility network voltage phasors and the distributed generator voltage phasors.

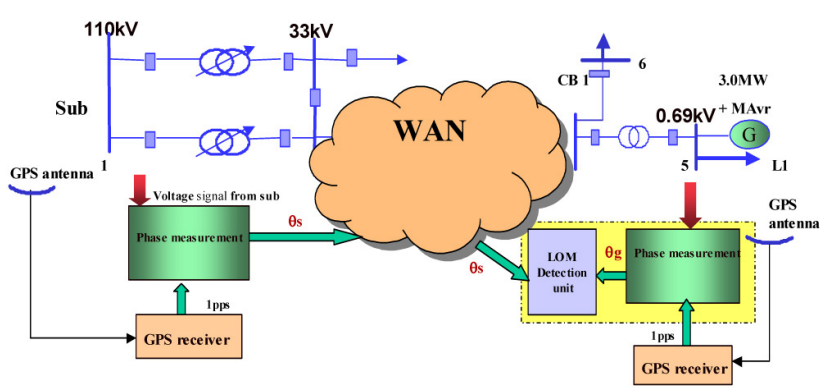

Fig. 15. System using angular difference to detect islanding.

Phasors are important state variables which represent both the magnitude and phase angle of the power signal. A fundamental frequency phasor is normally calculated using a DFT (Discrete Fourier transform) based on a one-power frequency cycle window. The IEEE standard 1344 [23] defines the start of the second as the absolute time reference for establishing the phasor phase angle value. If the maximum value of the AC power signal happens at the Coordinated Universal Time (UTC) second rollover, i.e. it is in phase with the cosine function synchronized to UTC, the angle will be 0 degree [23].

\subsection{Algorithms of the proposed technique}

The proposed LOM detection system in Fig. 15 consists of two GPS synchronised phasor measurement units (PMU) and a processor based islanding detection unit. One PMU is located at a utility substation and is used to measure the phase angle $\theta$ s of a utility voltage reference with respect to a GPS time stamp. This is then sent via a broadcast radio message or WAN to an islanding detection unit at the distributed generator site. The other PMU is installed at the generator-utility intertie and measures the phase angle of the distributed generator $\theta \mathrm{g}$.

The LOM detection unit calculates the phase angle difference between the DG terminal voltage and the utility substation voltage $\theta_{S G}$. It then compares this with the initial phase angle difference $\theta_{S G 0}$. If the resulting value 7 exceeds the threshold (eqn.2), a trip signal is issued. In order to ensure the stability of the proposed method during network faults, a voltage interlock signal is utilised in the scheme. If the terminal voltage of the DG or the voltage of the mains at the substation falls below a preset limit, the tripping signal from the detection unit is blocked. In the simulation the limit is set to $0.8 \mathrm{pu}$. A trip signal will only be sent to the inter-tie circuit breaker if conditions (2) and (3) are both satisfied.

$$
\Delta \theta=\left|\theta_{S G}-\theta_{S G 0}\right|>\theta_{\text {threshold }}
$$

$$
V>V_{\lim i t}
$$

In addition, to eliminate the phase error caused by the change of network configuration, the initial phase angle difference is updated periodically during the steady state. The block diagram for the LOM Detection Unit is presented in Fig. 16.

Since this proposed method compares the relative angular difference from the current state to its initial state, the phase shift due to the transformers connected between the two measuring points does not cause a problem. The main advantage of using the relative angular difference as the basis for a LOM detection system is the reliability 
obtained during system disturbances. This is illustrated using the simulation scenarios listed below.

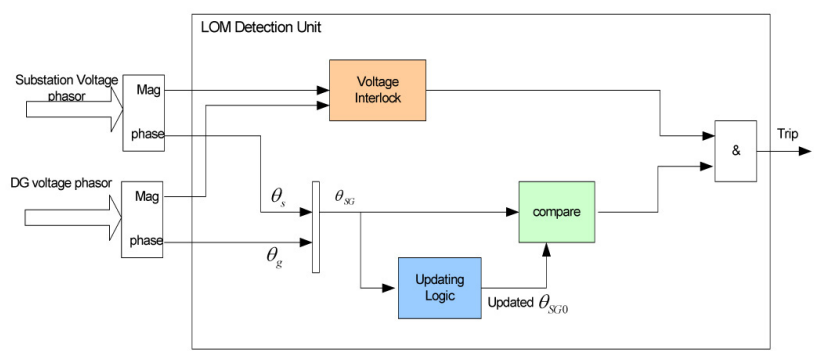

Fig. 16. Block diagram of proposed LOM detection unit.

The angle of the positive sequence voltage is used in the proposed detection scheme. This is because faults have less influence on positive sequence quantities as compared to the single-phase values normally used by LOM relays.

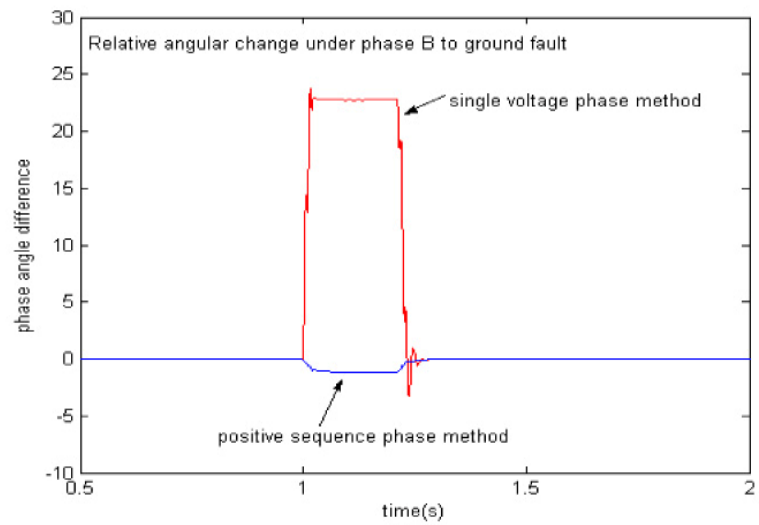

Fig. 17. Single phase vs. positive sequence phase method.

The effect of a single phase to ground fault on the phase angle derived from a single-phase voltage signal or a positive sequence voltage component was investigated using the simulator. The single-phase angle was measured using the phase A voltage signal and the fault was applied to phase B. The relative angular changes derived from these two methods are presented in Fig. 17. It is apparent that the angular change derived from the single-phase method is significantly larger than that observed using the positive sequence method. Therefore the latter is adopted in the proposed protection scheme.

\subsection{Simulation scenarios}

The proposed LOM protection scheme was evaluated using the similar test scenarios as applied to the conventional ROCOF relay.

Case-a. When considering the switching scenario discussed previously, simulation results show that the proposed protection remained "correctly" stable. The changes seen in the relative angular difference were very small during a switching operation.

Case-b. The frequency transient caused a by loss of bulk generation was simulated. There is no mal-operation of the proposed islanding detection; unlike a ROCOF relay the proposed protection remains stable.

Case-c. Simulation results show that the proposed protection remains stable when a three-phase fault occurs on an adjacent feeder. Although there is a sudden change in the angular difference seen during the fault, the difference soon returns to its original value once the fault is cleared.

These results illustrate the stability of the proposed LOM detection method during system transients. The technique can reliably discriminate between a loss of mains leading to the tripping of the generator-utility intertie circuit breaker and other types of transient events for which the system must remain stable.

Simulation was also conducted to test the performance of proposed LOM scheme at different power imbalances. The simulation results are presented in Fig. 18.

Detection time vs power imbalance

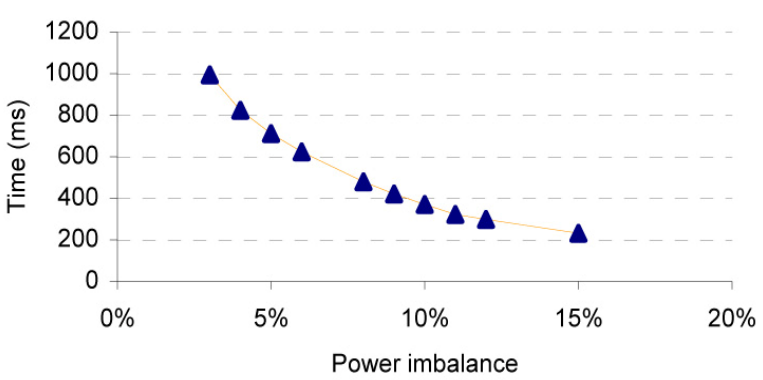

Fig. 18. Detection time of proposed LOM technique at different power imbalances.

The proposed LOM detection scheme can detect the islanding correctly when the power imbalance is greater than $3 \%$. The larger the power imbalance the faster the protection operates. It is noticed that the detection time of the proposed protection scheme is much longer than a ROCOF relay (range from $50 \mathrm{~ms}$ to $200 \mathrm{~ms}$ ). However, considering the nominal setting for the auto-recloser in the distribution network, $3 \mathrm{~s}$ in Great Britain and $3 \mathrm{~s}$ to $10 \mathrm{~s}$ in Northern Ireland, the detection time is acceptable. However, the authors recognise, these are only simulation studies and in reality, the proposed scheme would be more sensitive since an islanded system cannot hold the same frequency as the main utility frequency. The frequency difference between the formed island and the utility 
network will produce an angular change and eventually this will lead to the tripping of the inter-tie breaker. Further work is required to investigate this problem and to determine a realistic sensitivity value.

\section{Conclusion}

The paper discussed various techniques for islanding detection and described in detail why ROCOF and vector shift relays are the most popular. A simulator was used to investigate why the stability of both types of relays maybe affected by network and load switching, short-circuit faults and in the case of a ROCOF relay the loss of bulk generation or the tripping of a transmission feeder. Finally, to enhance the reliability of Loss of Mains protection, a new islanding detection technique based on a GPS synchronized phasor measurement system was proposed. Simulation results show that the new technique is significantly more stable than a conventional ROCOF relay, but further work is required before it can be considered a reliable solution to the problems of detecting an islanded distributed generator.

\section{References}

[1] Jenkings, N.; Allan, R.; Crossley, P.; Kirschen, D.; and Strbac, G., "Embedded Generation " IEE Power and Energy Series 31, IEE 2000.

[2] Econnect Ltd "Islanded Operation of Distribution Network", DG/CG/00026/00/00 DTI/pub URN 05/5912005.

[3] UK Electricity Association 1991, "Engineering recommendation G.59/1: Recommendations for the connection of Embedded Generating Plant to the regional electricity companies' Distribution System.

[4] O'Kane,P. and Fox,B., ' Loss of mains detection for embedded generation by system impedance monitoring'. IEE 6th International conference on Developments in Power System Protection, pp 95-98, March 1997.

[5] Salman, S.K.; King, D.J.; 'Monitoring changes in system variables due to islanding condition and those due to disturbances at the utilities' network', IEEE Transmission and Distribution Conference, April 1999 Vol. 2. pp460 - 465.

[6] COOPER, C.B., 'Standby generation problems and prospective gains from parallel running', International power system protection conference, Singapore, 1989.

[7] Usta, O.; Redfern, M.A.; Barrett, J.I.; 'Protection of dispersed storage and generation units against islanding', Proceedings. of 7th Mediterranean Electrotechnical Conference, April 1994 pp976 - 979.

[8] Redfern, M.A.; Barrett, J.I.; Usta, O., 'A new loss of grid protection based on power measurements', Sixth Int. Conf. On Developments in Power System Protection, 1997, pp.91-94.

[9] Redfern, M.A., USTA., O., Fielding, G., and Walker,E.P., "Power based algorithm to provide loss of grid protection for embedded generation", IEE Proc., Gener.Trans.Distrib.,1994, vol. 141, (6),pp.640-646.

[10] Salman, S.K., King, D.J., and Weller, G.:'New loss of mains detection algorithm for embedded generation using rate of chane of voltage and changes in power factorss' Seventh IEE Int. Conf. On Developments in Power System Protection, 2001, pp.82-85.

[11] Salman, S.K.; 'Detection of embedded generator islanding condition using elliptical trajectory technique', Sixth International Conference on Developments in Power System Protection, March 1997 Page(s):103-106.

[12] Pai, F., and Huang, S.: 'A detection algorithm of islanding prevention of dispersed consumer-owned storage and generating units', IEEE Tran., Energy Convers, 2001, 16, (4), pp. 346-351.

[13] Jang, S. and Kim, K.: 'An islanding detection method for distributed generations using voltage unbalance and total harmonic distortion of current', IEEE trans. on Power Delivery, 2004, vol. 19, (2), pp. 745-752 LOM-[14].

[14] Warin, J.W., "Loss of Mains Protections", ERA Conference on Circuit Protection for Industrial and Commercial Installations,London, 1990.

[15] Ye, Z., et. al; 'Evaluation of anti-islanding schemes based on nondetection zone concept' IEEE Transactions on Power Electronics, vol. 19, Issue 5, Sept. 2004 pp1171 - 1176.

[16] Kim, J.E.; Hwang, J.S.; 'Islanding detection method of distributed generation units connected to power distribution system' International Conference on Power System Technology, 2000. vol. 2.

[17] Xu, W., Mauch, K., "An Assessment of Distributed Generation Islanding Detection Mehtods and Issues for Canada", CETC-Varennes 2004-074 (TR) 411INVERT, July, 2004.

[18] Engineering Technical Report (ETR) 113, notes of guidance for protection of embedded generating plant up to $5 \mathrm{MW}$ for operation in parallel with public electricity suppliers' distribution systems, 1995 Electricity association.

[19] Mozina, C.J., 'Interconnection protection of IPP generators at commercial/industrial facilities', IEEE Trans. on Industry Applications, vol. 37, No. 3, 
May/June 2001, pp. 681-688.

[20] Econnect Ltd "Assessment of Islanded Operation of Distribution Networks and Measures for Protection", ETSU K/EL/00235/REP DTI/pub URN 01/1119 2001.

[21] CRAIG,L., and JENKINS,N.: "Islanding and self excitation of wind turbines". European Wind Energy Association Special Topic conference on Integration of wind power plants in the environment and electric systems, Rome, Italy, 1996.

[22] Beddoes, A., Thomas, P. and Gosden, M., 'Loss of mains protection relay performances when subjected to network disturbances/event', 18th International Conference on Electricity Distribution, Turin, June 2005.

[23] IEEE Power system relaying committee of the power engineering society. 2003. C37,118. IEEE Standard for Synchrophasors for Power System.

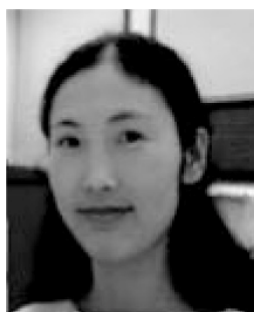

\section{Xiaolin Ding}

She graduated from UMIST in 2002 with a degree of MSc. in Electrical engineering. She is currently a Ph.D student of electrical power and energy systems research group at Queen's University of Belfast.

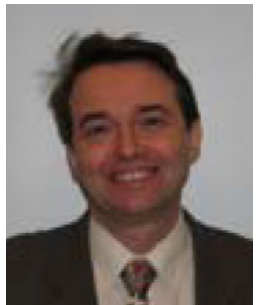

\section{Peter. A. Crossley}

He received his BSc from UMIST in 1977 and $\mathrm{PhD}$ from University of Cambridge in 1983. He is a Professor of Electrical Engineering at Queen's University of Belfast (QUB), UK. . He has been involved in the design and application of digital protection relays and systems for 26 years, first with GEC, then with ALSTOM and UMIST, and later with QUB. He has published over a 150 technical papers. His research interests are power system protection, embedded generation, condition monitoring of power plants, and fault location.

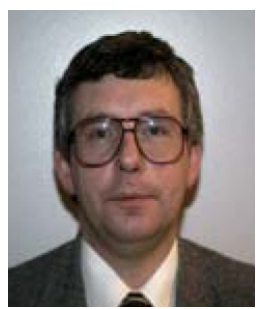

\section{John. Morrow}

He received the B.Sc. Ph.D. degrees from Queen's University Belfast in 1982 and 1987, respectively. Currently, he is a Lecturer in electric power with research and consulting interests in electric power systems, power system instrumentation, and gen-set controllers at Queen's University Belfast, where he has been since 1987. 